\title{
BRINGING TEXT MINERS AND BIOLOGISTS CLOSER
} TOGETHER

\section{Anália Lourenço ${ }^{1}$, Sónia Carneiro ${ }^{1}$, Rafael Carreira², Miguel Rocha², Isabel Rocha ${ }^{1}$, Eugénio C. Ferreira ${ }^{1}$}

${ }^{1}$ IBB - Institute for Biotechnology and Bioengineering, Centre of Biological Engineering ${ }^{2}$ Department of Informatics / CCTC University of Minho 
- W ho are we?

- R esearch and D evebpm ent areas

- Dom ains ofexpertise

- a Note, our literature $\mathrm{m}$ ining workench:

$-\mathrm{A}$ in $\mathrm{s}$

- Contributions

- Finalrem arks. 


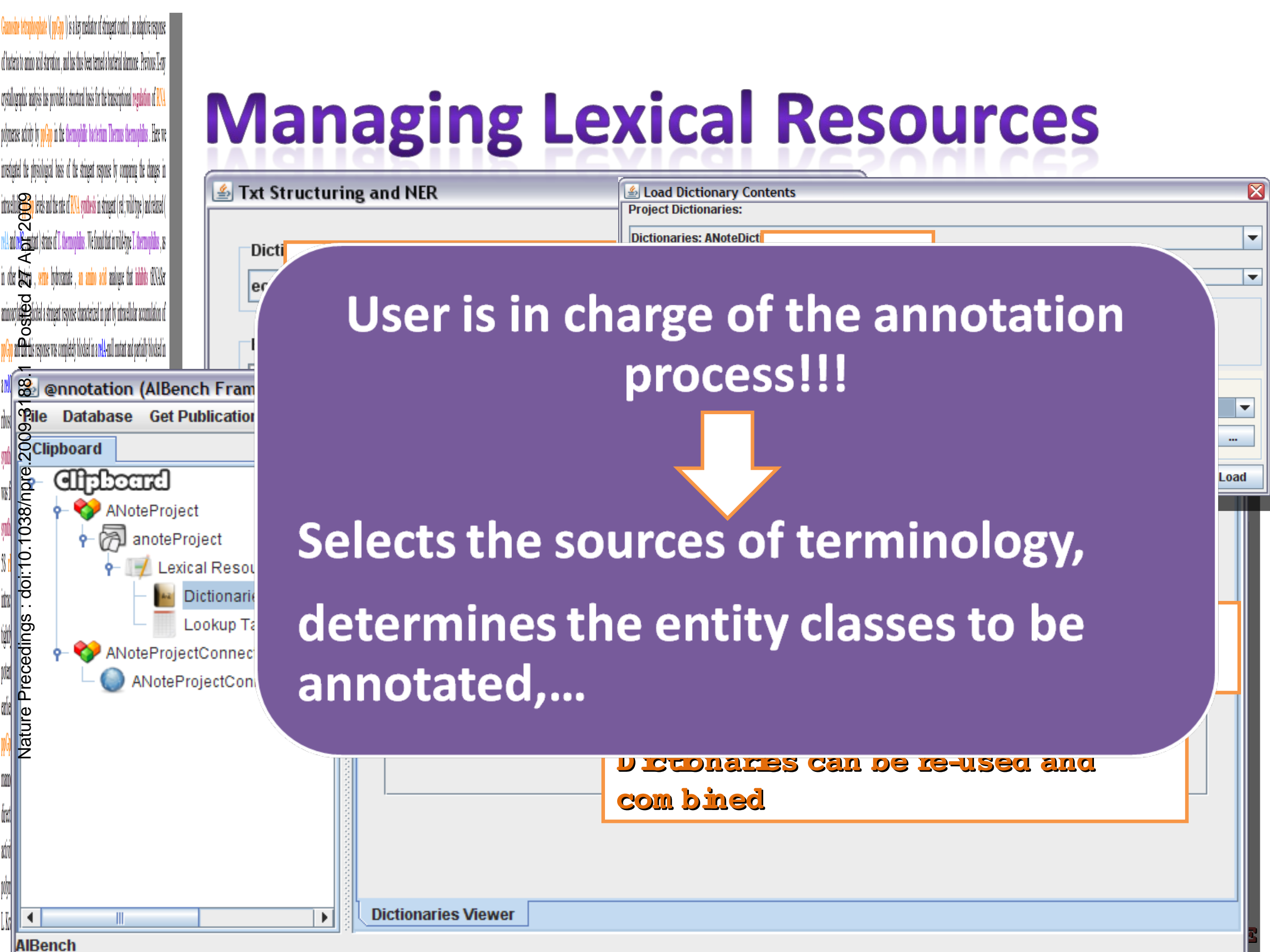


